\title{
An Estimation of Land Surface Temperatures from Landsat ETM+ images for Durban, South Africa
}

\author{
A. Ngie 1,3* $^{\text {; K. Abutaleb }}{ }^{2,3}$; F. Ahmed ${ }^{3}$; O. J' Taiwo; A.A. Darwish'; M. Ahmed ${ }^{2}$ \\ ${ }^{1}$ University of Johannesburg, South Africa \\ ${ }^{2}$ National Authority for Remote Sensing and Space Sciences, Cairo, Egypt \\ ${ }^{3}$ University of the Witwatersrand, Johannesburg, South Africa \\ * Corresponding author: email: adelinengie@gmail.com
}

\begin{abstract}
Population increase within urban environments especially in the developing countries, has posed a need to understand the urban climates. While the importance of urban climates cannot be overemphasized, acquiring knowledge about contributing factors to urban climates can be challenging. Measuring land surface temperatures is one of the ways to acquire such knowledge which could be an uphill task if done manually. However, satellite remote sensing data could be applied to spatially estimate such factors. Land surface temperatures (LST) were estimated from the thermal bands of the Landsat Enhanced Thermal Mapper Plus (ETM+) using remote sensing and geographic information system (GIS) techniques. In addition, meteorological data which included air temperature and relative humidity for the same satellite image dates were used in the analysis. Results showed that Durban metropolitan area is experiencing a major heat island over the city centre with some micro ones around the metro. Comparing the LST results to the landuse/cover of the city showed the UHI phenomenon is a reality with a $3^{\circ} \mathrm{C}$ and $4^{\circ} \mathrm{C}$ LST increase over the city centre of Durban for winter and summer seasons respectively in 2012 and being attributed greatly to the human activities within the area that has led to increase thermal radiation from land surface over highly dense and paved areas.
\end{abstract}

Keywords: Urban growth, urban heat Island, land surface temperatures, satellite remote sensing

\section{INTRODUCTION}

The human race is slowly but surely resettling more and more into more transformed environments known as urban areas. According to the United Nation Population Division (2008), almost two third of the world's population will be living within urban areas by mid of the $21^{\text {st }}$ century. It had been earlier ascertained that $70 \%$ of this urban population would be in developing countries which seems to be experiencing excessive high rates of urban growth (UNDP, 1994). The transformations within these areas have resulted in its natural vegetation cleared up and replaced with concrete pavements of roads and/or buildings. Hence, there is a need to understand the dynamics of urban climates as a result of these transformations for the wellbeing of these dwellers. 
When solar radiations hit the earth's surface, they are either absorbed or reflected back into the atmosphere which is dependent on the land surface material. Vegetation has been proven to absorb more of these radiations for its process of photosynthesis; meanwhile the concreted pavements reflect more of it (Wong \& $\mathrm{Yu}, 2005)$. In the case of the dark concreted surfaces, they absorb these radiations during the day and released at night as emissions. It is this reflected or emitted solar energy and the latent heat flux that influences the urban temperatures, causing them to be warmer than surrounding areas- a phenomenon known as urban heat island (UHI).

The UHI phenomenon is usually evaluated from land surface temperatures (LST). The influence on urban climate from the resulting increase in LST can impact on the development of meteorological events such as increased precipitation, and boosts energy demands, poses threats to environmental quality as well as longterm sustainability of localities, while potentially contributing to global warming (Yang and Liu, n.d.; Kikegawa et al., 2006). It also has an economical impact on the energy usage by local residents. Hence, it may induce unchecked increases in fossil-fuel consumption for cooling and its consequent increases in the anthropogenic carbon dioxide emission, which could contribute to global warming (Huang et al., 2008). There are also devastating human health impacts as has been shown by the excess mortality of 15,000 people in France during the heat wave of the 2003 summer, especially in the largest agglomerations (Hémon \& Jougla, 2003).

UHI may be identified by measuring surface or air temperatures. Surface temperatures have an indirect but significant influence on air temperatures. For example, parks and vegetated areas, which typically have cooler surface temperatures, contribute to cooler air temperatures (Wong \& Yu, 2005). Dense built-up areas, on the other hand, typically lead to warmer air temperatures. Because air mixes within the atmosphere, though, the relationship between surface and air temperatures is not constant (Voogt \& Oke, 2003; Nichol, 2005). Therefore the measurement of UHI is done at various levels and by different tools. The LST could be measured at scale point atmospheric temperatures from meteorological stations. However, these measurements are usually not true representation of the LST as they are limited in extent to a scale of area (Mirzaei \& Haghighat, 2010). Some researchers have tried to cover a larger area by mounting thermometers on a car and driving around a city but this is also challenged by the time factor and labour intensive (Huang et al., 2008). Some of the measurements also get subjective and unreliable.

Monitoring from satellite images has become more attractive because remotely sensed data are almost in real time, and cover a large area (Streutker, 2003). Technological advancements and free availability of these satellite data has translated into a growing base of studies through the LST estimation establishing an existence of the UHI phenomenon within cities across the globe (Voogt \& Oke, 2003; Joshi \& Bhatt, 2012) with the Asian continent being the most researched and the African continent the least (Ngie et al., 2014). Hence, the purpose of this paper was to adopt some existing remote sensing techniques to estimate LST 
from Landsat ETM+ imageries for 2002 and 2012 in one of South Africa's fast growing metropolitan cities, Durban.

\section{A. Study area and data acquisition}

The city of Durban is a metropolitan coastal area situated within the eThekwini municipality of the KwaZulu-Natal province in South Africa (Figure 1). The municipality is made up of a combination of land use/land cover and completely bordered to the east by the Indian Ocean through which warm sea currents flow from north to south and to the west by Pietermaritzburg which is the second largest city in the province. Topographically it is hilly with few flat areas, except around the central business district and the harbour being the busiest port in Africa. It has a mild subtropical climate with warm wet summers and moist to dry winters. The total surface area of this municipality is $2292 \mathrm{~km}^{2}$ with a population of 3442361 inhabitants (census 2011: Stats SA, 2012).

Satellite data were acquired over two different seasons: winter (June-August) and summer (JanuaryMarch) during the day periods for each season for two different years in order to assess the measurements over time. The data selected was for 2002 and 2012 Landsat ETM+ images. Where suitable 2012 images were not available (due to high cloud cover) in a given season, 2011 images within the same season were acquired. For instance summer images were selected in 2011. In total six images were selected for this study. Ancillary data was also collected which included meteorological data of temperature and relative humidity obtained from the Durban South weather station for the corresponding dates for which satellite images were acquired. 


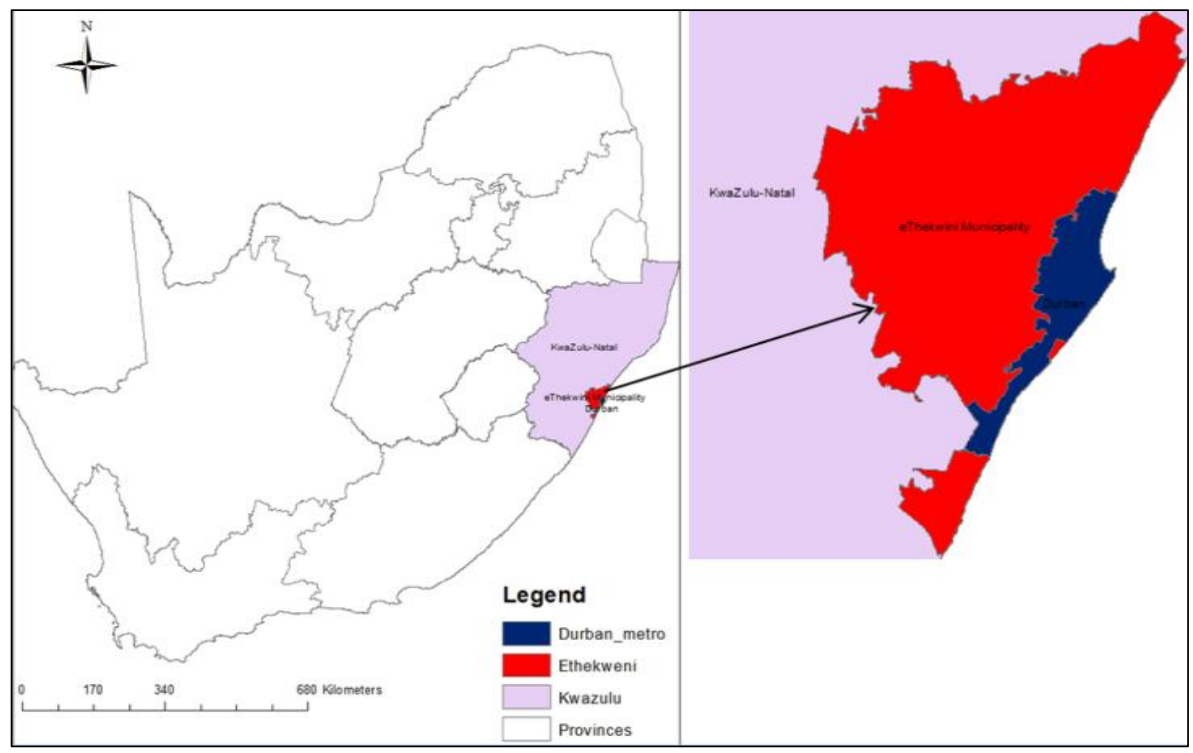

Figure 1: Map of South Africa showing the Durban metropolitan city

\section{METHODOLOGY TO RETRIEVE LST FROM SATELLITE IMAGES}

\section{B. LST retrieval methods}

Landsat TM and ETM+ have a single thermal band (band 6) which is the thermal infrared (TIR) channel that records radiation within a 10.4-12.5 $\mu \mathrm{m}$ spectral range of the electromagnetic spectrum. Different LST retrieval methods have been developed according to different data sources (thermal bands on a sensor), such as the split-window, temperature/emissivity separation, mono-window, and the single-channel methods (Qin et al., 2001, Sobrino et al., 1996; Jimenez-Munoz \& Sobrino, 2003). Among these methods three can be applied to Landsat data; these include the radiative transfer equation, mono-window algorithm and singlechannel algorithm.

Although all of these methods can provide good results, some of them such as the radiative transfer equation can only yield results with in situ atmospheric parameters captured simultaneously as the satellite passes over the study area. In addition, the mono-window algorithm can get better results than the singlechannel algorithm with a root mean square deviation of $0.9^{\circ} \mathrm{C}$ (Sobrino, et. al., 2004). It has been recently proven to yield better accuracy for the retrieval of LST from Landsat images as illustrated for Hong Kong with a $0.7^{\circ} \mathrm{C}$ error (Liu \& Zhang, 2011).

This study therefore makes use of the mono-window algorithm to retrieve the LST from the ETM+ imagery for the city of Durban. The algorithm is based on thermal radiance transfer equation and requires three parameters: emissivity, transmittance and effective mean atmospheric temperature to retrieve LST from Landsat multispectral imagery (Qin et al., 2001). 
The spatial model to retrieve LST from Landsat data for this study was designed using ERDAS Imagine ${ }^{\circledR}$ spatial model tool (Sun et al., 2010; Liu \& Zhang, 2011). The model requires two measured parameters: near-surface air temperature and relative humidity (RH) simultaneously measured as the satellite passed over the study area. These data were obtained from the local weather stations situated within the study areas. The two parameters were then converted to atmospheric transmittance and effective mean atmospheric temperature. The third parameter (emissivity) was calculated from the normalized difference vegetation index (NDVI).

\section{Mono-window algorithm}

1. Conversion of digital number into spectral radiance:

The satellite sensors measure reflectances from the earth surface as digital numbers (DN) representing every pixel of the image. The DN data from Landsat was converted to spectral radiance using Equation (1):

$$
L_{\lambda}=L_{\lambda \min }+\left(L_{\lambda \max }-L_{\lambda \min }\right) \times \frac{\left(Q_{\lambda D N}-Q_{\lambda \min }\right)}{\left(Q_{\lambda \max }-Q_{\lambda \min }\right)}
$$

Where $L_{\lambda}$ is at-sensor spectral radiance;

$L_{\lambda \max }$ is maximum at-sensor spectral radiance;

$L_{\lambda \min }$ is minimum at-sensor spectral radiance;

$\left(Q_{\lambda \max } \mathrm{Q}=255\right)$ and $\left(Q_{\lambda \min } \mathrm{Q}=1\right)$ are the maximum and minimum $\mathrm{DN}$ value of pixels respectively and, $Q_{\lambda D N} \mathrm{Q}$ is the DN value of pixel.

For Landsat $\mathrm{ETM}^{+}$data, equation (1) can be rewritten in two dimensions depending on the low and high gain bands of the thermal band and expressed in equations 2 and 3.

The low gain band which provides an expanded dynamic range with lower radiometric resolution (sensitivity), has less saturation at high DN values ${ }^{1}$ and expressed thus:

$$
L_{61}=0.0671\left(Q_{\lambda D N}-1\right)
$$

$>$ The high gain band has a higher radiometric resolution (sensitivity) although it has a more restricted dynamic range (ibid) and expressed thus:

$$
L_{62}=0.0372\left(Q_{\lambda D N}-1\right)+3.2
$$

2. Conversion of spectral radiance into at-sensor brightness temperature:

The conversion formula is:

${ }^{1}$ http://landsathandbook.gsfc.nasa.gov/data_properties/prog_sect6_4.html. Accessed 27/02/2014 


$$
T_{i}=\frac{K_{2}}{\ln \left(\frac{K_{1}}{L_{\lambda}}+1\right)}
$$

Where $T_{i}$ is at-sensor temperature in Kelvin, $\mathrm{K}_{1}$ and $\mathrm{K}_{2}$ are pre-launch calibration constants and, $\mathrm{L}_{\lambda}$ is the spectral radiance in watts per metre squared steradian micron $\left(\mathrm{W} /\left(\mathrm{m}^{2 *} \mathrm{~s} \mathrm{~s}^{*} \mu \mathrm{m}\right)\right)$. For ETM+ the calibration constants are:

$$
\begin{aligned}
& K_{1}=666.09\left(\mathrm{~W} /\left(\mathrm{m}^{2 *} \mathrm{sr}^{*} \mu \mathrm{m}\right)\right) \\
& K_{2}=1282.71 \mathrm{~K}
\end{aligned}
$$

\section{Calculation of NDVI}

NDVI is a simple graphical indicator usually used to analyze remote sensing measurements, and assess if observed target includes green vegetation or not. NDVI is one of the outputs that run into the model to retrieve LST using equation (5)

$$
N D V I=\frac{\text { NIR-R }}{\text { NIR+R }}
$$

Where NIR is Near Infra-red band and $\mathbf{R}$ is the red band

\section{Estimation of emissivity}

In this study, the land surface emissivity was derived from the NDVI as proposed by Zhang (2006). From the NDVI results obtained above (Equation 5) corresponding land emissivity values were established (Table 1).

Table 1: Estimation of land surface emissivity from NDVI (Adopted from Zhang, 2006)

\begin{tabular}{|c|c|}
\hline NDVI & $\begin{array}{c}\text { Land surface } \\
\text { emissivity }\left(\boldsymbol{\varepsilon}_{\mathbf{i}}\right)\end{array}$ \\
\hline NDVI $<-0.185$ & 0.995 \\
\hline$-0.185 \leq \mathrm{NDVI}<$ \\
0.157 & 0.970 \\
\hline $0.157 \leq \mathrm{NDVI} \leq$ \\
0.727 & $1.0094+0.0047 *$ \\
Ln(NDVI) \\
\hline NDVI $>0.727$ & 0.990 \\
\hline
\end{tabular}

5. Estimation of atmospheric transmittance

Atmospheric transmittance which is defined as the capacity of the atmosphere to transmit electromagnetic energy is dependent on the air mass penetrated by radiations, as well as on the amount of water vapour and 
dust in the air. It varies for radiations of different wavelengths; the smaller the atmospheric absorption and scattering of light, the greater the atmospheric transmittance.

(i) Calculation of water vapour content

The calculation of water vapour is done through equation (6) which entails deriving relative humidity. Relative humidity can be defined as the ratio of water vapour at a given temperature to the saturation water vapour pressure at the same temperature (Wagner and Pruß, 2002).

$$
\boldsymbol{R H}=\frac{P_{a}}{P_{s}} \times \mathbf{1 0 0}
$$

Where RH is the relative humidity;

$P_{a}$ is the actual water vapour pressure;

$P_{s}$ is the saturation water vapour pressure.

Equation (6) is rewritten to obtain $\mathrm{P}_{\mathrm{a}}$ as follows:

$$
\boldsymbol{P}_{a}=\boldsymbol{P}_{s} \frac{\boldsymbol{R H}}{\mathbf{1 0 0}}
$$

The saturation water vapour pressure $\left(P_{s}\right)$ at a given temperature $(\mathrm{K})$ can be calculated (Wagner and $\operatorname{Pruß,2002):}$

$$
P_{s}=P_{c} * e^{\left[\frac{T_{C}}{T}\left(C_{1} \vartheta+C_{2} \vartheta^{1.5}+C_{3} \vartheta^{3}+C_{4} \vartheta^{3.5}+C_{5} \vartheta^{4}+C_{6} \vartheta^{7.5}\right)\right]}
$$

Where:

$$
\begin{aligned}
& T=\text { ambient temperature in } \mathrm{K} \\
& \mathrm{P}_{\mathrm{s}}=\text { Saturation water vapour pressure }(\mathrm{hPa}) \\
& \mathrm{T}_{\mathrm{c}}=\text { Water critical temperature }(647.096 \mathrm{~K}) \\
& \mathrm{P}_{\mathrm{c}}=\text { Critical pressure }(220640 \mathrm{hPa}) \\
& \mathrm{C}_{1}=-7.85951783 \\
& \mathrm{C}_{2}=1.84408259 \\
& \mathrm{C}_{3}=-11.7866497 \\
& \mathrm{C}_{4}=22.6807411 \\
& \mathrm{C}_{5}=-15.9618719 \\
& \mathrm{C}_{6}=1.80122502
\end{aligned}
$$

And

$$
\vartheta=1-\frac{T}{T_{c}}
$$


(ii) Atmospheric transmittance estimation

Atmospheric transmittance is then estimated on the basis of some linear equations derived from statistical regression analysis (Qin et al., 2001). These equations relate the atmospheric transmittance to the water vapour content $\left(\mathrm{g} / \mathrm{cm}^{2}\right)$ (Equation (8)). Based on the results obtained for water vapour content in this study, corresponding atmospheric transmittance equations were selectedError! Reference source not found.. The air temperature ( $t_{a}$ ) profiles were set as $t_{a}<15^{\circ} \mathrm{C}$ being low and $t_{a}>15^{\circ} \mathrm{C}$ as being high.

6. Calculation of mean atmospheric temperature

Equations (9) and (10) are used to estimate the atmospheric mean temperature $\left(\mathrm{T}_{\mathrm{a}}\right)$ based on given near surface air temperature (To) (Qin et al., 2001):

For mid-latitude summer

$$
T_{a}=16.0110+0.92621 T_{0}
$$

For mid-latitude winter

$$
T_{a}=19.2704+0.91118 T_{0}
$$

7. LST retrieval from the mono-window algorithm

In the mono-window algorithm, the LST value is calculated using Equation 11 but with two unknowns (C and D) being realised through Equations 12 and 13. The three required parameters (emissivity, transmittance and effective mean atmospheric temperature) are included in the equation as follows:

$$
\begin{aligned}
& T_{s}=\frac{\left(a+b T_{i}\right)(1-C-D)+D\left(T_{i}-T_{a}\right)}{C}+T_{i} \\
& D=\left(1-\varepsilon_{i}\right)\left[1+\left(1-\varepsilon_{i}\right) t\right] \\
& C=\mathcal{E}_{i} * t
\end{aligned}
$$

Where: $T_{s}$ is LST (K); $T_{i}$ is at-sensor temperature $(\mathrm{K}) ; \boldsymbol{\varepsilon}_{i}$ is emissivity estimated from NDVI; $t$ is atmospheric transmittance calculated from water vapour content; $T_{a}$ is mean atmospheric temperature; $a=-67.355351$, and $\mathrm{b}=0.458606$.

\section{RESULTS AND DISCUSSION}

\section{Spatial distribution of LST and intensity in Durban}

The estimated LST values from the satellite images indicated spots of higher and lower temperatures across the city for both years (2002 and 2012). The spot of increased LST were located around the central 
business district (CBD) where the harbour is located, industrial areas as well as highly dense unplanned or semi-planned residential areas. While the areas of lower LST values were found at the peripheral areas of the city which included recreational parks with vegetation, agricultural lands or planned residential areas with gardens. Through these results, the UHI could be established by a deduction of the lower surrounding temperatures from the higher temperatures of the CBD. The LST magnitude varied over the years as well as over the seasons of $2.4^{\circ} \mathrm{C}, 2.5^{\circ} \mathrm{C}$ (winter 2002 and 2012); 3.0 ${ }^{\circ} \mathrm{C}, 2.9^{\circ} \mathrm{C}$ (summer 2002 and 2012 of about $2.5^{\circ} \mathrm{C}$ and $3^{\circ} \mathrm{C}$ respectively. Pinetown and Phoenix which are about $20 \mathrm{Km}$ north west and $17 \mathrm{Km}$ north respectively of the city of Durban are some of the suburban areas experiencing sharp increase in the temperature values as a result of the high industrial activities (

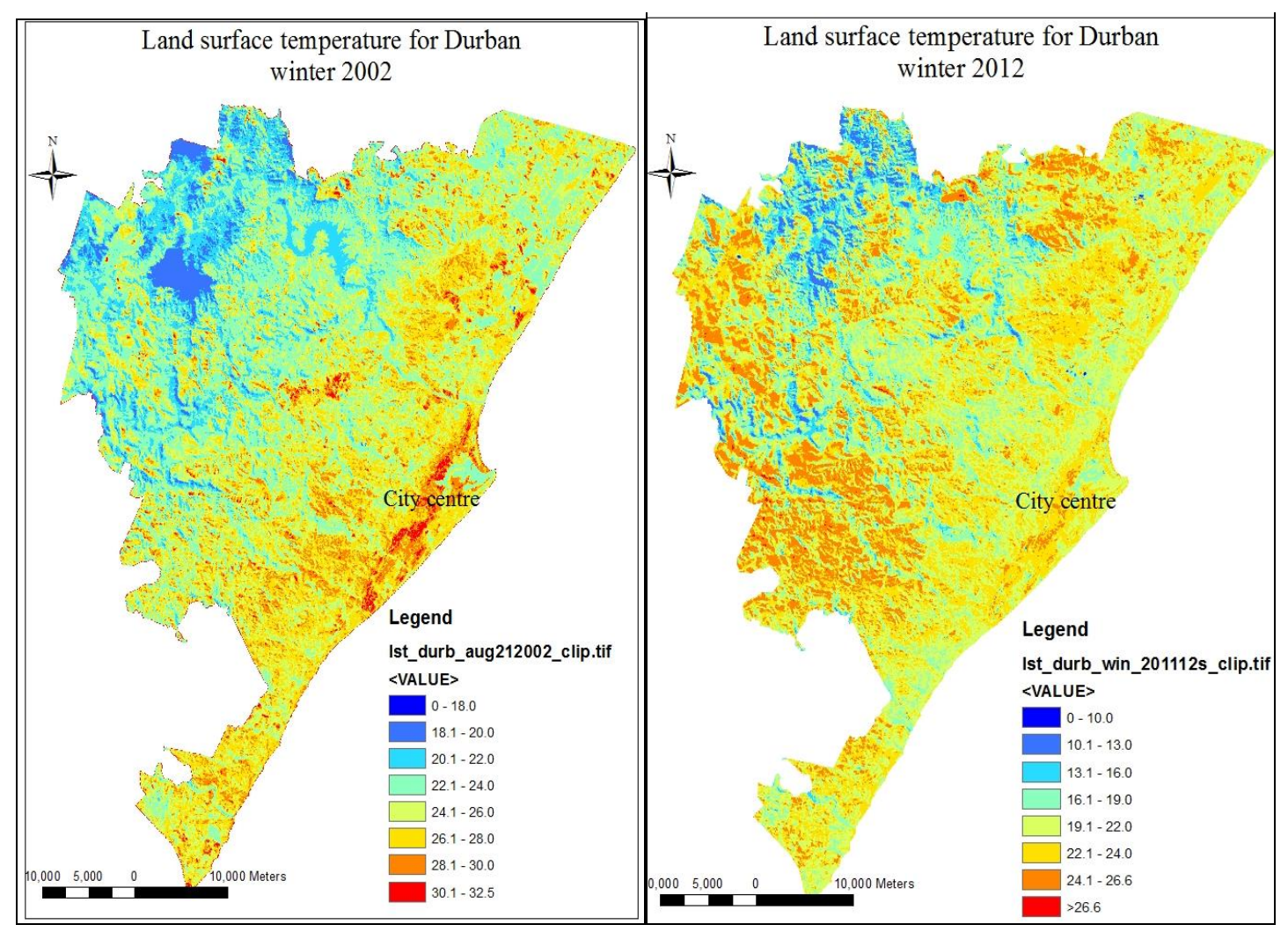

Figure 2). From the above results it is glaring therefore that the UHI effect is a reality during the winter and summer seasons over the city centre which is along the harbour as well as suburban industrial and highly dense unplanned areas.

The changes in land use/cover (LULC) pattern in relation to urbanization also impact on the intensity and spatial pattern of the UHI effect (Chen et al., 2006; Meng \& Liu, 2013). This has been affirmed with different land uses influencing UHI differently as a result of the surface properties (Hung et al., 2006). Huang et al. (2008) used four types of land covers in Nanjing (China) namely urban bare concrete cover, urban woods or the shade of trees, urban water areas and urban lawn with their microclimates examined, and the UHI analyzed using air temperature data measured at four fixed observation spots. The results revealed among others that the microclimate of these four types of land covers had significantly different 
impacts on UHI in the order of bare concrete cover>lawn>water areas>woods or the shade of trees during daytime with reversed order during nighttime.

According Mallick et al. (2009) investigating the characteristic difference in LST over Delhi (India) confirmed the influence of land covers on the UHI phenomenon. So too did our study over Durban since the higher temperature sites corresponded to the commercial/retail, industrial and the huge unplanned periurban settlements. While the island sinks or lower LST values corresponded to the recreational parks, undeveloped/vegetated land and the water body around the harbour. 

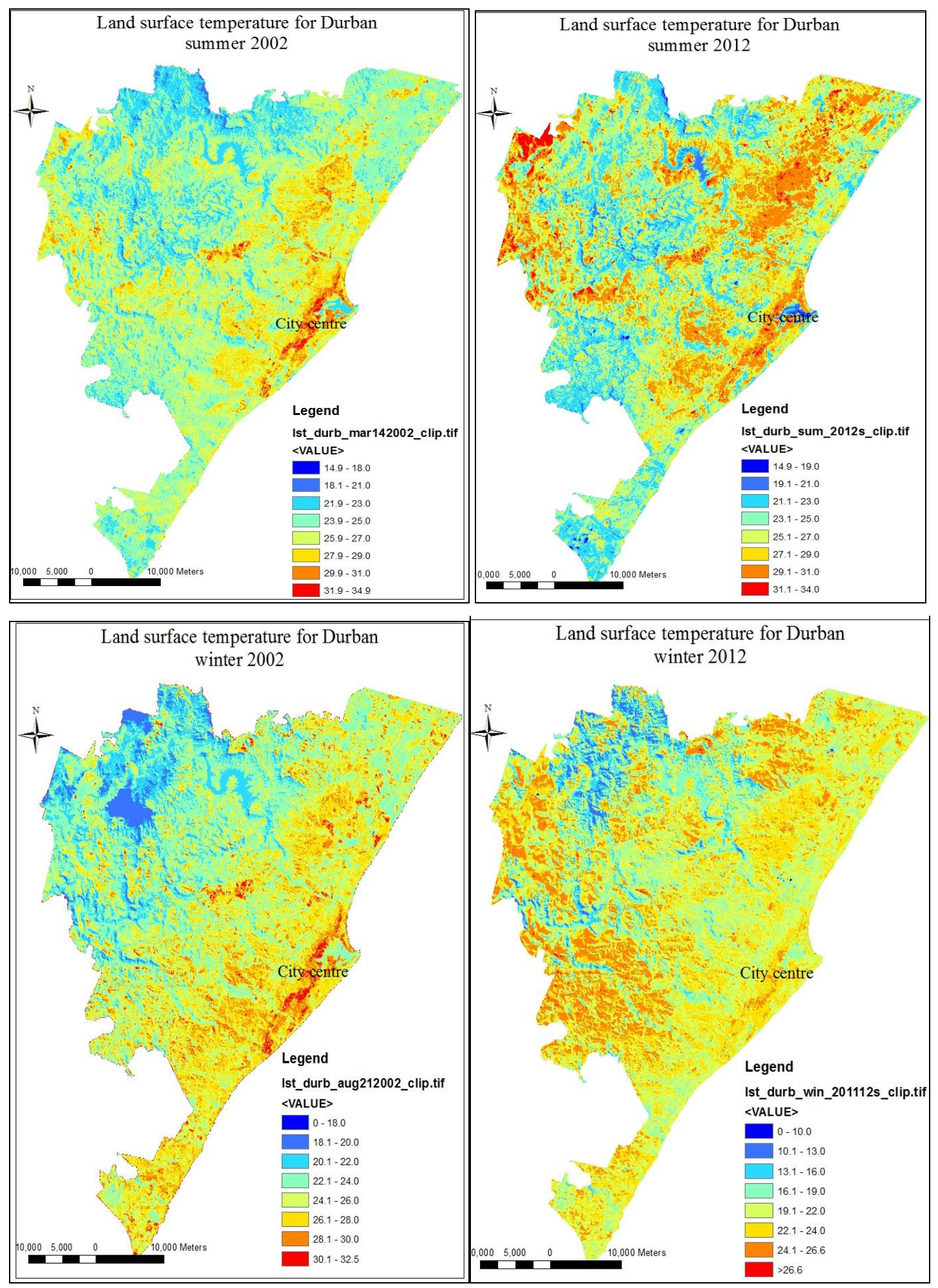

Figure 2: LST maps for Durban

Mapping the LST values produces an isothermal map with closed contours on the urban area and wider contours over surrounding areas. This thermal profile is represented graphically by the isothermic curve that rises over the city centre, but contrasts with the characteristic low flattened curve of the surrounding areas. A typical thermal profile shows undulations of cliff, plateau, peak and depressions (

Figure 3). The surrounding area's thermal field shows interruptions by a steep temperature gradient at the surrounding/urban central boundaries (i.e. cliff), and thereafter a steady but weaker horizontal gradient of 
increasing temperature (i.e. plateau) is prolonged until reaching the highest temperature point at the urban core or city centre (i.e. peak). The profile was created $5 \mathrm{~km}$ across the city centre, meaning the centre lies around $3 \mathrm{~km}$ on the profile.
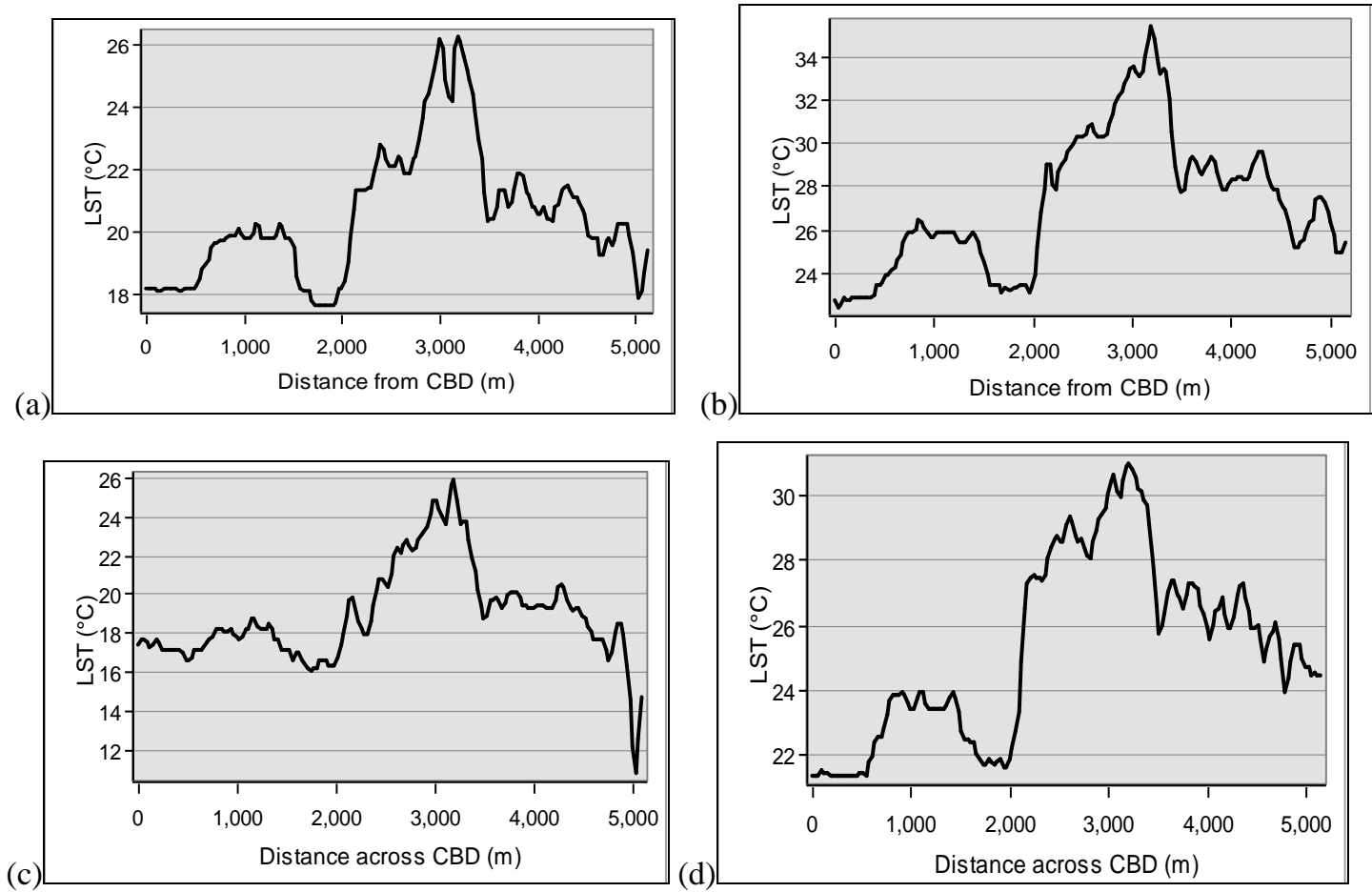

Figure 3: UHI profiles over Durban city centre (CBD) - (a) Winter 2002 (b) Summer 2002 (c) Winter 2012 (d) Summer 2012

The uniformity of this island profile's shape pattern generally indicates some depressions due to the presence of particular heat points (micro urban heat islands) associated with features such as parking lots, malls, industrial facilities, etc, and some rises due to the presence of particular heat sinks associated with features such as parks, open fields, water bodies, etc (Imhoff et al., 2010). The difference between the warmest urban point and the least surrounding area temperatures defines the intensity or magnitude of the UHI. Given that the city centre was around the $3 \mathrm{~km}(3000 \mathrm{~m})$ mark, the LST value at this point is recorded from which the value from the surrounding areas between $500-1000 \mathrm{~m}$ is subtracted and results being the UHI magnitude.

The results also showed that the LST was not proportional to urbanization over time. For winter 2002 and 2012, the magnitude was higher in the former than the latter even with increased population size. This could be linked to the increase awareness of the importance of urban planning to environmentally sustainable cities which policy makers and town planners have engaged from 2005 . These results were in conformity once again to results obtained in other studies in China where such interventions reduced the magnitude of 
the phenomenon (Cai et al., 2011). However, there will be need to monitor this phenomenon over this city in consideration of the landscape.

\section{E. Relationship between the observed air temperature and the estimated LST}

Statistical regression analysis was used to establish a relationship between the estimated LST values and the measured air temperature values from weather station within the city of Durban. The analysis was done using mean temperature values for both scenarios over the city and both seasons (winter and summer). This was a result of the challenge in acquiring individual or precise temperature values at the same time the satellite passed over the city. The analysis resulted in an $\mathrm{R}^{2}$ of 0.95 (Figure 4). Therefore, results revealed the fitness of the mono-window algorithm in estimating LST values. The difference between the estimated LST values and the measured air temperature values can be associated partly with the effects of surface roughness on surface temperature and emissivity not considered (Weng, 2001) and partly because of atmospheric impurities which can obstruct the smooth passage of radiant energy (Brooks, 2006).

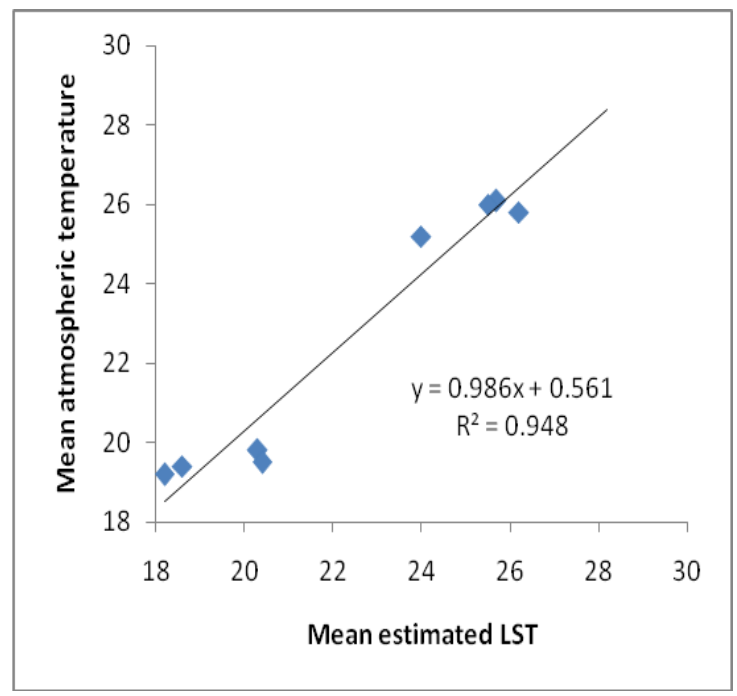

Figure 4: Relationship between the observed air temperature and the estimated LST

\section{CONCLUSION AND RECOMMENDATIONS}

LST estimation from satellite images using remote sensing techniques over the city of Durban was successful as illustrated by the high $\mathrm{R}^{2}$ of $95 \%$ in the validation of the mono-window algorithm. The slight increase in the LST values over the CBD to its surrounding areas is an indication of UHI effect in this metropolitan city. The seasons (winter and summer) certainly contributed to this effect as proven by the differences in the magnitudes yielded from the various seasons. Therefore, more could be done in investigating this effect as regarding the contributing factors and their magnitudes over this city.

The study recommends that proper urban planning could avert the effects of this phenomenon. It is vital to investigate the LST values over various surfaces in order to understand the contributors according land use and/or cover of the urban areas. Identified contributors could be decreased or intermixed with sites that 
absorb solar radiations such as vegetated areas as well as cooler roofs (Zinzi \& Fasano, 2009; Vardoulakis et al., 2014).

\section{ACKNOWLEDGEMENT}

Appreciations to the National Research Foundation (NRF- South Africa) and the Ministry of State for Scientific Research- Egypt for providing funds for the project through the Joint Research grant under the South African / Egypt Research Partnership Programme Bilateral Agreement (UID78639). We also acknowledge the input of the anonymous reviewers.

\section{REFERENCES}

Arnfield, A.J., 2003: Two decades of urban climate research: a review of turbulence, exchanges of energy and water, and the urban heat island. International Journal of Climatology 23: 1-26.

Basar, U.G., S. Kaya and M. Karaca, 2008: Evaluation of urban heat island in Istanbul using remote sensing techniques. Commission VII, WG VII/5. The International Archives of the Photogrammetry, Remote Sensing and Spatial Information Sciences Vol. XXXVII. Part B7. Beijing 2008.

Brooks, D. R., 2006: Monitoring Solar Radiation and Its Transmission through the Atmosphere. The GLOBE Program's Aerosols, Water Vapor, and UV-A Monitoring Projects V 2.0 http://www.pages.drexel.edu/ brooksdr/DRB/papers/UsingTheSun/using.htm Accessed 20/11/2013

Cai, G., M. Du and Y. Xue, 2011: Monitoring of urban heat island effect in Beijing combining ASTER and TM data. International Journal of Remote Sensing, 32(5): 1213-1232.

Chen, X.L., H.M. Zhao, P.X. Li and Z.Y. Yin, 2006: Remote sensing image-based analysis of the relationship between urban heat island and land use/cover changes. Remote Sensing of Environment 104: 133-146.

Hémon D. and E. Jougla, 2003: Estimation de la surmortalité et principales caractéristiques épidémiologiques (Evaluation of comparatively high death rate and epidemiologic main features). Technical report, INSERM. http://www.sante.gouv.fr/htm/actu/surmort_canicule/rapport_complet.pdf Accessed 8 May 2012.

Huang, L., J. Li, D. Zhao and J. Zhu, 2008: A fieldwork study on the diurnal changes of urban microclimate in four types of ground cover and urban heat island of Nanjing, China. Building and Environment 43: 7-17.

Hung, T., D. Uchihama, S. Ochi and Y. Yasuok, 2006: Assessment with satellite data of the urban heat island effects in Asian mega cities. International Journal of Applied Earth Observation and Geoinformation 8: 34-48. 
Imhoff, M.L., P. Zhang, R.E. Wolfe and L. Bounoua, 2010: Remote sensing of the urban heat island effect across biomes in the continental USA. Remote Sensing of Environment 114: 504-513.

Jiménez-Muňoz, J.C. and J.A. Sobrino, 2003: A generalized single-channel method for retrieving land surface temperature from remote sensing data. Journal of Geophysical Research 108: 4688-4694.

Joshi, J. P. and B. Bhatt, 2012: Estimating temporal Land Surface Temperature using remote sensing: A study of VADODARA urban area, Gujarat. International Journal of Geology, Earth and Environmental Sciences ISSN: 2277-2081 (Online) Vol. 2 (1) May-August, 123-130.

Kikegawa, Y., Y. Genchi, H. Kondo and K. Hanaki, 2006: Impacts of city-block-scale countermeasures against urban heat-island phenomena upon a building's energy-consumption for air-conditioning. Applied Energy 83: 649-68.

Liu, L. and Y. Zhang, 2011: Urban Heat Island analysis using the Landsat TM data and ASTER Data: A case study in Hong Kong. Remote Sensing 3:1535-1552.

Lo, C.P. and D.A. Quattrochi, 2003: Land-Use and land-cover change, urban heat island phenomenon, and health implications: A remote sensing approach. Photogrammetric Engineering and Remote Sensing 69(9): 1053-63.

Mallick, J., A. Rahman, P.V. Hoa and P.K. Joshi, 2009: Assessment of night-time urban surface temperature -- LULC relationship for thermal urban environment studies using optical and thermal satellite data. 7th FIG Regional Conference Spatial Data Serving People: Land Governance and the Environment - Building the Capacity Hanoi, Vietnam, 19-22 October 2009.

Meng, F. and M. Liu, 2013: Remote-sensing image-based analysis of the patterns of urban heat islands in rapidly urbanizing Jinan, China. International Journal of Remote Sensing 34(24): 8838-8853.

Mirzaei, P.A and F. Haghighat, 2010: Approaches to study Urban Heat Island - Abilities and limitations. Building and Environment 45: 2192-2201.

Ngie, A., K. Abutaleb, F. Ahmed, A. Darwish and M. Ahmed, 2014: Assessment of Urban Heat Island using remotely sensed imagery: A Review. South African Geographical Journal, http://dx.doi.org/10.1080/03736245.2014.924864

Nichol, J., 2005: Remote sensing of urban heat islands by day and night. Photogrammetric Engineering and Remote Sensing 71(5): 613-621.

Oke, T.R., 1973: City size and the urban heat island. Atmospheric Environment 7: 769-779.

Qin, Z., A. Karnieli and P. Berliner, 2001: A mono-window algorithm for retrieving land surface temperature from Landsat TM data and its application to the Israel-Egypt border region. International Journal of Remote Sensing 18: 3719-3746. 
Sailor, D.J. and H. Fan, 2002: Modeling the diurnal variability of effective albedo for cities. Atmospheric Environment 36(4): 713-25.

Sobrino, J.A., J.C. Jimenez-Munoz and L. Paolini, 2004: Land surface temperature retrieval from LANDSAT TM 5. Remote Sensing of Environment 90, 434-440.

Sobrino, J.A., Z. L. Li, M.P. Stoll and F. Becker, 1996: Multi-channel and multi-angle algorithms for estimating sea and land surface temperature with ASTER data. International Journal of Remote Sensing 17:2089-2114.

Statistics South Africa (Stats SA), 2012: Census 2011 Statistical release- P0301.4/Statistics South Africa: Pretoria 78pp. www.statssa.gov.za

Streutker, D.R., 2003: Satellite-measured growth of the urban heat island of Houston, Texas. Remote Sensing of Environment 85: 282-289.

Sun, Q., J. Tan and Y. Xu, 2010: An ERDAS image processing method for retrieving LST and describing urban heat evolution: A case study in the Pearl River Delta Region in South China. Environment Earth Science 59, 1047-1055.

UNDP (United Nations Development Programme), 1994: Human Development Report. Oxford University Press: New York.

United Nation Population Division, 2008: World urbanisation prospects, the 2007revision. Unitd Nations: New York.

Vardoulakis, E., D. Karamanis and G. Mihalakakou, 2014: Heat island phenomenon and cool roofs mitigation strategies in a small city of elevated temperatures. Advances in Building Energy Research. DOI: $10.1080 / 17512549.2014 .890537$

Voogt, J. 2002: Urban Heat Island. In Munn, T. (ed.) Encyclopedia of Global Environmental Change, Vol. 3. Chichester: Wiley.

Voogt, J.A. and T.R. Oke, 2003: Thermal remote sensing of urban climates. Remote Sensing of Environment 86: 370-84.

Wagner, W. and A. Pruß, 2002: The IAPWS formulation 1995 for the thermodynamic properties of ordinary water substance for general and scientific use. Journal of Physical and Chemical Reference Data 31(2), pp. 387535.

Wang, K., J. Wang, P. Wang, M. Sparrow, J. Yang and H. Chen, 2007: Influences of urbanization on surface characteristics as derived from the Moderate-Resolution Imaging Spectroradiometer: A case study for the Beijing metropolitan area. Journal of Geophysical Research 112(D22S06): 1-12. 
Weng, Q., 2001: A remote Sensing-GIS evaluation of urban expansion and its impacts on surface temperature in the Zhujiang, Delta, China. International Journal of Remote Sensing 22(10): 1999-2014.

Weng, Q., H. Liu and D. Lu, 2007: Assessing the effects of LULC patterns on thermal conditions using landscape metrics in city of Indianapolis, United States. Urban Ecosystems 10: 203-219.

Weng, Q., D. Lu and J. Schubring, 2004: Estimation of land-surface temperature-vegetation abundance relationship for urban heat island studies. Remote Sensing of Environment 89: 467-83.

Wong, N. H. and C. Yu, 2005. Study of green areas and urban heat island in a tropical city. Habitat International 29: 547-558.

Zhang, Y., 2006: Land surface temperature retrieval from CBERS-02 IRMSS thermal infrared data and its applications in quantitative analysis of urban heat island effect. Journal of Remote Sensing 10:789-797.

Zhang, Z., M. Ji, J. Shu, Z. Deng and Y. Wu, 2008: Surface urban heat island in Shanghai, China: Examining the relationship between land surface temperature and impervious surface fractions derived from Landsat ETM+ imagery. The International Archives of the Photogrammetry, Remote Sensing and Spatial Information Sciences. Vol. XXXVII. Part B8. Beijing 2008.

Zinzi, M. and G. Fasano, 2009: Properties and performance of advanced reflective paints to reduce the cooling loads in buildings and mitigate the heat island effect in urban areas. International Journal of Sustainable Energy 28(1-3): 123-139. 